\title{
Conservative Treatment of Malignant Fibrous Histiocytoma of the Kidney: A Case Report
}

\author{
Hernani Gil-Julio Fernando Vázquez-Alonso Ignacio Puche-Sanz \\ Antonio J. Fernández-Sánchez José M. Cózar-Olmo \\ Department of Urology, Virgen de las Nieves Universitary Hospital, Granada, Spain
}

\author{
Key Words \\ Sarcoma • Malignant fibrous histiocytoma • \\ Conservative renal surgery
}

\begin{abstract}
Primary renal malignant fibrous histiocytoma is an extremely rare disease. There are neither clinical nor radiological signs to distinguish it from the most common renal cell carcinoma. Its prognosis is poor because of its tendency to locally recur and metastasize. Therefore, early diagnosis and proper treatment are very important. We present the case of a 66-yearold woman diagnosed with primary renal malignant fibrous histiocytoma who underwent partial nephrectomy. After 41 months' follow-up, there was no evidence of any recurrence. To our knowledge, this is the first reported case of conservative surgery for this kind of tumor.
\end{abstract}

Copyright $\odot 2012$ S. Karger AG, Basel

\section{Introduction}

The term malignant fibrous histiocytoma (MFH) was first described by O’Brien and Stout in 1964 and includes a variety of pleomorphic soft-tissue sarcomas, derived from histiocytes with fibroblastic transformation potential [1]. MFH is a common, mesenchyma-derived sarcoma affecting soft tissues, predominantly of the limbs and retroperitoneum. Although it is rare, it can also affect intraperitoneal organs [2].

Its clinical presentation depends on the primary tumor location, in addition to the nonspecific systemic symptoms induced by the neoplastic process. Abdominal pain can occur in patients with intraperitoneal localization. Presentation as fever of unknown origin is very rare and is probably caused by tumor necrosis and the release of inflammatory factors.

\section{Case Report}

We present a 66-year-old woman with a previous history of Still's disease, 5 abortions, osteoporosis, type 2 diabetes, obesity, repetitive renal colic and a right simple renal cyst. She was admitted to our hospital with the chief symptom of fever of unknown origin. The findings from physical examination, as well as the serum and urinary data, were unremarkable. A $17-\mathrm{mm}$, well-defined, mid-renal mass, suggesting renal cell carcinoma (RCC), was detected on computerized tomography (CT) (fig. 1). The patient underwent open partial nephrectomy with an uneventful postoperative course. However, histological study revealed a pleomorphic MFH with an abundant giant-cell population and free surgical borders (fig. 2,3). No adjuvant therapy was administered. After a 41-month follow-up period, there was no evidence of recurrence.

\section{KARGER}

Fax +41 613061234

E-Mail karger@karger.ch

www.karger.com
(C) 2012 S. Karger AG, Basel

1015-9770/12/0061-0046\$26.00/0

Accessible online at:

www.karger.com/cur
Hernani Gil-Julio

Virgen de las Nieves Universitary Hospital

Departament of Urology

Avda. Fuerzas Armadas, 2

ES-18014 Granada (Spain)

Tel. +34 6260631 51, Fax +34 9580201 45, E-Mail mavangos@gmail.com 


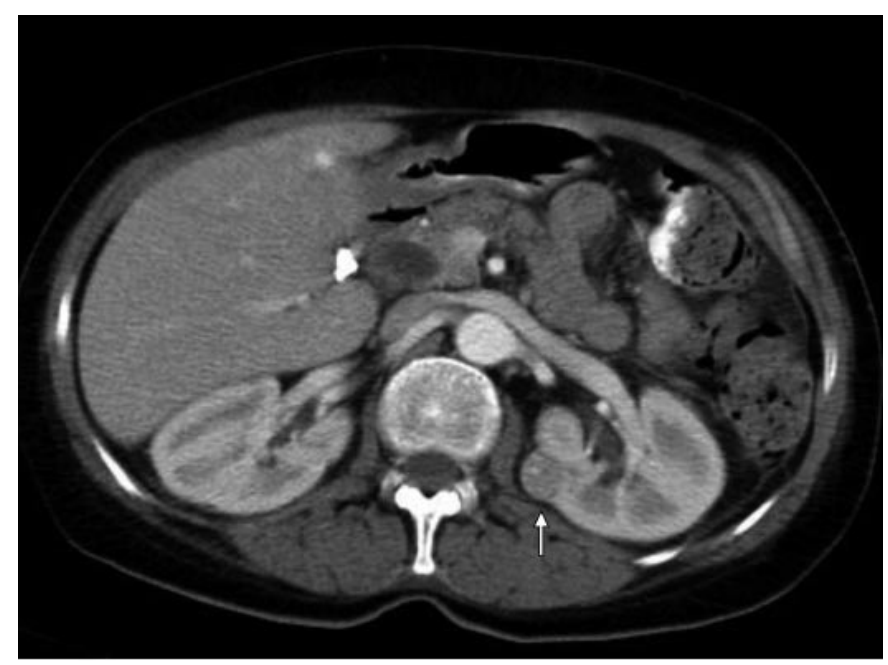

Fig. 1. Abdominal CT shows a well-defined, mid-renal mass, of left kidney.

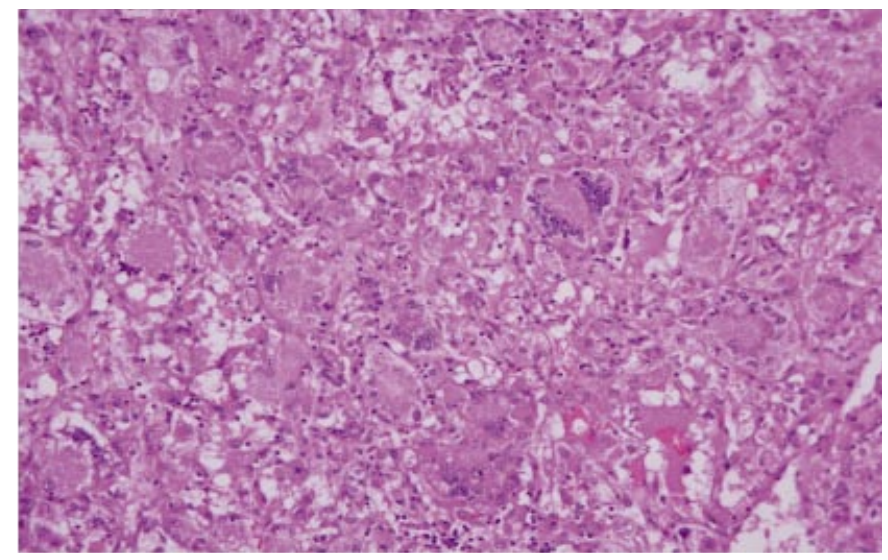

Fig. 2. Multinucleated giant cells in addition to dysplastic cells with large amounts of cytoplasm (hematoxylin-eosin, original magnification $\times 20$ ).

\section{Discussion}

MFH has been reported in almost every site of the body. It is more frequent in the limbs, retroperitoneum, head, neck and cardiac muscle. It rarely affects intraperitoneal organs, and its localization in organs of the genitourinary tract, such as the prostate, bladder or kidneys, is exceptional $[2,3]$.

Conservative Treatment of Malignant

Fibrous Histiocytoma of the Kidney

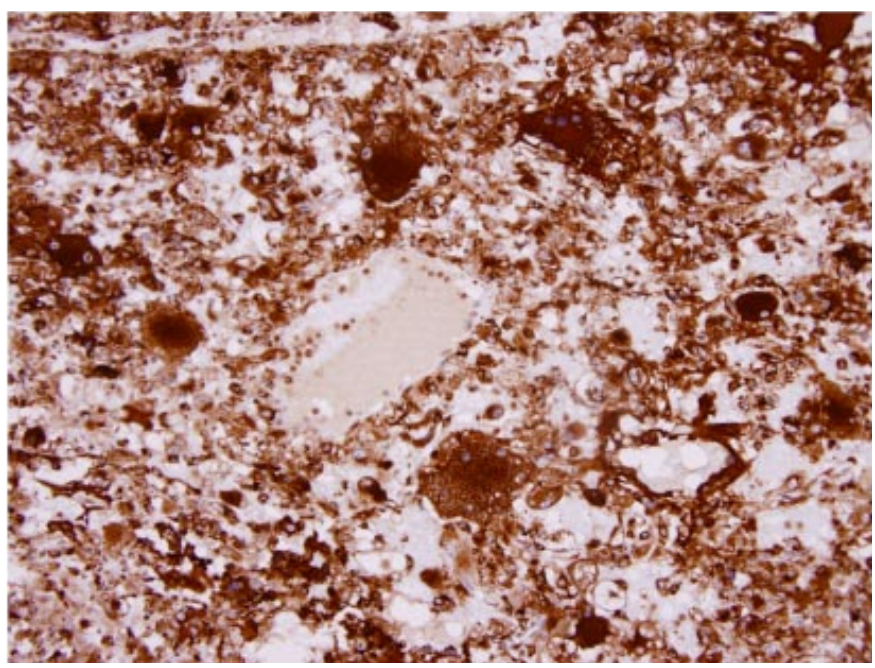

Fig. 3. Immunohistochemistry shows CD68-positive multinucleated giant cells and dysmorphic cells, characteristic of histiocytic elements (original magnification $\times 20$ ).

MFH is considered to be the most common soft-tissue sarcoma in adults. There is an incidence peak in a patient's 70's, and it is less likely in individuals younger than 40 years of age. It is more frequent in males [3, 4]. It can be divided into 5 subgroups according to the predominant tumor component: storiform-pleomorphic, myxoid, giant-cell, inflammatory and angiomatoid [4]. Our case was of the giant-cell type, which has been described as the most aggressive.

MFH's mode of presentation is very different from one patient to another. Moreover, there are no key signs or symptoms and thus, it is usually only diagnosed in an advanced phase. The most common presentation is a progressively growing painless mass. When it is located intra- or retro-peritoneally, the patient may complain of abdominal distension and present with progressive enlargement of the abdominal perimeter, leading to the development of an abdominal hernia or varicocele. A constitutional syndrome can also be observed in these cases [4]. In our case, the diagnosis was incidentally made during the study of a long-lasting fever syndrome. In those cases reported in the literature in which kidneys were concerned, the most frequent presentation symptoms were flank pain, an abdominal palpable mass, weight loss and an overall bad feeling. Hematuria has been rarely reported, typically in association with RCC, which bleeds more frequently than MFH [3]. 


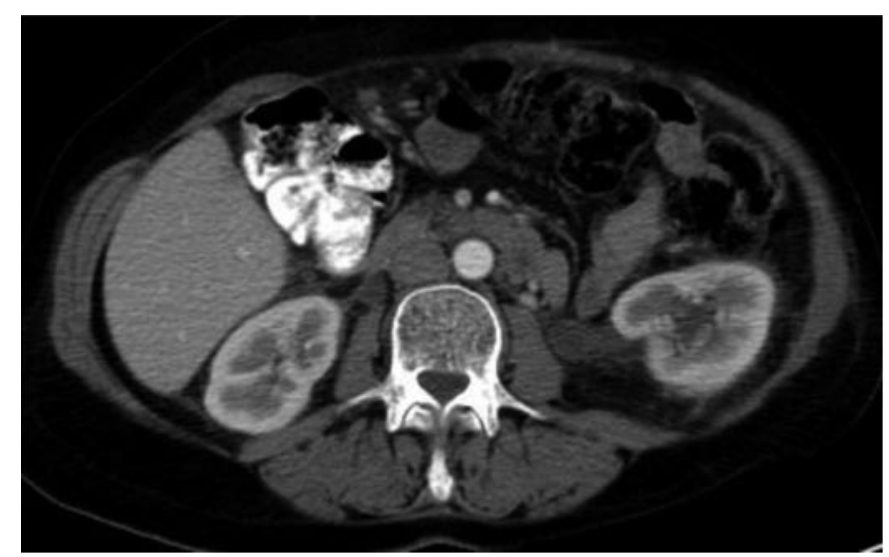

Fig. 4. Abdominal CT image after 41 months of follow-up.

The diagnosis of MFH is often made in advanced phases of the disease. Abdominal CT is the most accepted imaging test, although using abdominal CT in combination with positron emission tomography $\left({ }^{18} \mathrm{~F}-\mathrm{FDG}\right.$ $\mathrm{PET} / \mathrm{CT}$ ) has recently been proposed to have higher diagnostic reliability [5]. Differential diagnosis from RCC is difficult and is ultimately based on histopathological and immunohistochemical examination [3].

Surgery is the most common treatment for MFH [6]. It is well known that disease recurrence is highly likely [7], and therefore, wide extirpation of the tumor is recommended in order to guarantee free surgical borders. In the present case, we were dealing with a small mass, so it was decided to perform a partial nephrectomy. The surgical borders were microscopically confirmed to be free. As the vast majority of MFH cases are diagnosed in advanced phases, there is little collective experience with conservative approaches to the treatment of this condition. As far as we know, ours is the only case described in the literature.

MFH is an aggressive tumor with a high potential for local and distant recurrence months or even years after surgery [6]. The liver is the most common site of metastasis (64-70\% of cases). Other reports point to the lungs as the main location of distant dissemination (80$90 \%$ ), followed by the bones and the liver. Reports of lymph node involvement differ, depending on the series $(10-32 \%)[4,7,8]$. The elective treatment for metastatic disease is typically surgery when possible [6]. Palliative surgery is indicated when complete resection of the tumor is not possible [7,8].

The role of adjuvant radiotherapy and/or chemotherapy is still in discussion in the case of visceral retroperitoneal sarcomas. There are reports suggesting that there is no improvement in general survival with systemic chemotherapy [3]. However, it has recently been reported that the effectiveness of systemic chemotherapy could be improved by including neoadjuvant radiotherapy in the treatment regimen, even for high-grade sarcomas [6]. Other authors recommend chemoembolization as an alternative for treating non-resectable metastatic sarcomas that exhibit long-lasting stabilization [9].

The prognosis of retroperitoneal MFH is generally poor, reaching a risk of recurrence of more than $50 \%$ and a 5-year survival rate after diagnosis of only $14 \%$, which is likely due to the difficulty of the surgery and the typically delayed diagnosis [3, 10]. However, our case remains disease free after 41 months of follow-up (fig. 4).

To conclude, primary renal MFH is an extremely rare and very aggressive tumor with a high rate of recurrence and a low survival rate [6]. Although radical surgery is typically the treatment elected in selective and early-diagnosed cases, such as ours, conservative surgery is a feasible option. 


\section{References}

1 O'Brien JE, Stout AP: Malignant fibrous xanthomas. Cancer 1964;17:1445-1455.

$\checkmark 2$ Qureshi NA, Hallissey MT, Fielding JW, Gourevitch D: Primary intra-abdominal malignant fibrous histiocytoma presenting as pyrexia of unknown origin - report of a case with review of literatura. Int Semin Surg Oncol 2006;3:15.

> Kim SJ, Ahn BC, Kim SR, Kim YB, Joo HJ, Lee KB, Kim YS: Primary malignant fibrous histiocytoma of the kidney. Yonsei Med J 2002;43:399-402.

4 Weiss SW, Enzinger FM: Malignant fibrous histiocytoma: an analysis of 200 cases. Cancer 1978;41:2250-2266.
5 Hwang SS, Park SY, Park YH: The CT and F-FDG PET/CT appearance of primary renal malignant fibrous histiocytoma. J Med Imaging Radiat Oncol 2010;54:365-367.

-6 Sugihara T, Fujimura T, Kume H, Homma Y: Successful treatment of metastatic malignant fibrous histiocytoma of the kidney. Urol Int 2010;85:118-120.

7 Sabesan T, Xuexi W, Yongfa Q, Pingzhang $\mathrm{T}$, Ilankovan V: Malignant fibrous histiocytoma: outcome of tumours in the head and neck compared with those in the trunk and extremities. Br J Oral Maxillofac Surg 2006; 44:209-212.
8 Hsu HC, Huang EY, Wang CJ: Treatment results and prognostic factors in patients with malignant fibrous histiocytoma. Acta Oncol 2004:43:530-535.

$\checkmark 9$ Rajan DK, Soulen MC, Clark TW, Baum RA, Haskal ZJ, Shlansky-Goldberg RD, Freiman DB: Sarcomas metastatic to the liver: response and survival after cisplatin, doxorubicin, mitomycin-C, ethiodol, and polyvinyl alcohol chemoembolization. J Vasc Interv Radiol 2001;12:187-193.

10 Papadopoulos I, Rudolph P: Primary renal malignant fibrous histiocytoma: case report. Urol Int 1999;63:136-138.

\section{Erratum}

A spelling error occurred in the article: Umemoto et al: Intra-Operative Damage to the Pelvic Diaphragm Musculature and Difficulty in Exposure of the Urethra Are Risk Factors of Postoperative Urinary Incontinence after Laparoscopic Radica Prostatectomy: Review of Surgical Video. Curr Urol 2011;5:185-189. The third author Yoshiyuki Kojim should read Yoshiyuki Kojima. 